\title{
Desempenho de semeadoras-adubadoras de soja em Latossolo Vermelho muito argiloso com palha intacta de milho ${ }^{1}$
}

\author{
Ricardo G. Aratani ${ }^{2}$, Isabella C. de Maria ${ }^{3}$, Orlando M. de Castro ${ }^{3}$, \\ Afonso Peche Filho ${ }^{4}$, Aildson P. Duarte ${ }^{5} \&$ Ricardo A. D. Kanthack ${ }^{5}$
}

\begin{abstract}
RESUMO
Como a dificuldade da semeadura da soja sob grande quantidade de palha do milho safrinha intacta, sem a fragmentação ou incorporação dos resíduos, em solos muito argilosos, tem desmotivado a utilização do sistema plantio direto pelos agricultores da região paulista do Médio Paranapanema, objetivou-se, com este trabalho, comparar o desempenho quanto ao embuchamento, bem como avaliar a qualidade da semeadura entre semeadoras-adubadoras original e adaptada, na cultura da soja. O sistema modificado proporcionou menor número de paradas do conjunto trator-semeadora, em função de embuchamento. As freqüências de solo exposto e profundidades de deposição da semente e do sulco em ambas as semeadoras e, ainda, o número de plantas emergidas para a semeadora-adubadora modificada, apresentaram diferença significativa entre as linhas de semeadura. O desempenho das duas semeadoras-adubadoras avaliadas não foi satisfatório quanto à largura de revolvimento do solo e à uniformidade da profundidade de deposição da semente.
\end{abstract}

Palavras-chave: plantio direto, máquinas agrícolas, haste sulcadora

\section{Performance of soybean seed drills in Oxisol with intact corn straw}

\begin{abstract}
Soybean sowing under great amount of intact residues of off-season maize, without cutting or incorporation of residues in highly clayey soils has discouraged the farmers to adopt no-tillage (direct planting) in Médio Paranapanema region, São Paulo State, Brazil. The aim of this study was to compare the performance of an original and a modified no-tillage planter by minimizing the straw accumulation, and to evaluate the sowing quality. The modified planter system provided less number of stops due to straw accumulation. Both planter systems showed that uncover soil frequencies and depths of seeding and furrow presented significant differences between the sowed lines. The modified planter system expressed significant difference for number of emerged plants between the sowed lines. The performance of the both planters was not satisfactory for soil revolving width and uniformity of the depth of seeding.
\end{abstract}

Key words: no tillage, agricultural machines, chisel soil opener

1 Projeto financiado parcialmente pela Coopermota, Associação de Plantio Direto do Vale do Paranapanema e Semeato

2 Eng. Agrônomo, Convênio IAC-APTA Regional Médio Paranapanema/Coopermota, Rodovia SP 333, km 397, CP 263CEP.19800-000, Assis, SP. Fone: (18) 3321.2026,. E-mail: aratani@femanet.com.br

${ }^{3}$ IAC-APTA, Centro de Solos e Recursos Ambientais. CEP. 13020-902. Campinas, SP, (19) 3241.5188, icdmaria@iac.sp.gov.br, omcastro@iac.sp.gov.br

${ }^{4}$ IAC-APTA, Centro de Engenharia e Automação. CEP. 13201-970, Jundiaí, SP, (11) 4582.8155, peche@iac.sp.gov.br

${ }^{5}$ APTA Regional Médio Paranapanema. CEP.19802-970, Assis, SP. E-mail: aildson@aptaregional.sp.gov.br, kanthack@aptaregional.sp.gov.br 


\section{INTRODUÇÃO}

A região paulista do Médio Paranapanema caracteriza-se pelo cultivo de grãos, principalmente a soja, semeada no verão, e o milho safrinha, em sucessão, semeado no outonoinverno. Nos últimos anos, esta região vem apresentando aumento acentuado da área com o sistema plantio direto; entretanto, o principal fator que desmotiva a completa e sistemática utilização deste sistema, é a dificuldade da semeadura da soja sob grande quantidade de palhada do milho safrinha, conforme diagnóstico realizado junto aos produtores da região. Para facilitar a semeadura, o agricultor regional maneja a palhada com roçadoras e picadores, ou gradagens fechadas, fragmentando a palha em pedaços bem reduzidos, procedimento que facilita o processo de semeadura, porém promove aumento do tráfego na lavoura e, em conseqüência, aumenta o risco de compactação, acelera a decomposição vegetal e aumenta o custo operacional.

Os restos culturais deixados sobre o solo, formando cobertura morta, reduzem a erosão em relação a outros tipos de manejo que retiram ou enterram os resíduos (Silva \& Lombardi Neto, 1981). Lombardi Neto et al. (1988) relatam que $8 \mathrm{t} \mathrm{ha}^{-1}$ de resíduos culturais de milho apenas cortados e espalhados sobre um Latossolo Roxo distrófico com declive de $13 \%$, controlaram em $90 \%$ as perdas de solo e $80 \%$ as de água, no decorrer de dez meses; entretanto, a relação entre a erosão e a cobertura vegetal morta do solo pode ser influenciada pelo tipo e forma de manejo dos resíduos culturais (Lopes et al., 1987). Alves et al. (1995) afirmam que a decomposição biológica e o deslocamento físico dos resíduos culturais são processos seletivos, que atuam sobre as frações mais suscetíveis, enquanto as partes mais resistentes persistem no local, por longos períodos.

Um dos aspectos relevantes para o sucesso da lavoura no plantio direto é o desempenho da semeadora-adubadora, no que se refere ao corte eficiente dos restos culturais, à abertura do sulco e à colocação da semente e do fertilizante em profundidades corretas no solo e a manutenção da cobertura vegetal sob o solo. Também é importante que as máquinas apresentem adequada regularidade, com distribuição precisa de sementes e fertilizantes (EMBRAPA, 1994).

Araújo et al. (2001) relatam que em solos argilosos do Paraná, a alta resistência à penetração dos componentes rompedores, associada à elevada retenção de umidade desses solos, tem proporcionado freqüentes problemas durante a semeadura direta, por corte irregular da vegetação, embuchamentos, abertura irregular do sulco, aderência de solo nos componentes, profundidade de semeadura desuniforme, cobertura e compactação do solo sobre as sementes deficientes, afetando a uniformidade de emergência das plantas e, conseqüentemente, exigindo constantes adaptações das semeadoras-adubadoras à realidade regional.

Com este trabalho, objetivou-se avaliar o desempenho de semeadoras-adubadoras de plantio direto com e sem modificações no sistema de corte de palha e haste sulcadora, com ênfase na redução do problema de embuchamento, em área com grande quantidade de palha intacta de milho, em Latossolo Vermellho muito argiloso.

\section{MATERIAL E MÉTODOS}

As modificações mecânicas do sistema de corte de palha e haste sulcadora, foram introduzidas em uma semeadora-adubadora de plantio direto, modelo PAR 3600, de nove linhas para a cultura da soja, da marca Semeato e diferem do projeto original em quatro itens: 1) a substituição do disco de corte de palha liso original de $0,46 \mathrm{~m}$ por um de $0,51 \mathrm{~m}$ de diâmetro; 2) a substituição da haste sulcadora do solo original de 0,46 m por uma de 0,51 m de comprimento; 3) a substituição da garra de acoplamento original por uma que permite aumentar a defasagem dos conjuntos para 0,33 m; 4) a substituição das molas de pressão do disco de corte e da haste sulcadora por modelos mais reforçados e com angulação diferente visando à obtenção de um poder maior de corte.

Os testes das semeadoras original e modificada, foram realizados em um Latossolo Vermelho distroférrico com 68\% de argila, na Fazenda Santo Antônio, município de Florínea, SP. A área estava sendo cultivada em sistema plantio direto, há 4 anos, e apresentava 9,3 t ha-1 ${ }^{-1}$ em média, de resíduos vegetais intactos da cultura do milho, ou seja, sem fragmentação. A colheita do milho foi realizada no dia 17 de março de 2004 e a instalação do ensaio em 7 de abril de 2004, quando o solo apresentava consistência friável a plástica. A resistência do solo à penetração na área da avaliação, feita com auxílio de penetrômetro de impacto, indicou os valores 0,86; 1,81; 2,05 e 2,03 MPa, para as faixas de profundidade de 0 a 0,$10 ; 0,10$ a 0,$20 ; 0,20$ a 0,30 e 0,30 a $0,40 \mathrm{~m}$, respectivamente.

As semeadoras-adubadoras original e modificada, foram reguladas para o espaçamento de 0,45 m entre linhas e de-

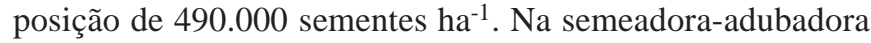
original, as profundidades do sulco e da deposição de semente foram, respectivamente, de 0,10 e de 0,03 a $0,04 \mathrm{~m}$, enquanto na modificada, 0,13 e de 0,04 a $0,05 \mathrm{~m}$. As sementes de soja utilizadas na semeadura eram da variedade IAC-22 e a adubação foi de $250 \mathrm{~kg} \mathrm{ha}^{-1}$ da fórmula NPK 0-30-10. Utilizouse um trator Ford 8630, com 135 cv de potência máxima no motor, para tracionar as semeadoras-adubadoras, proporcionando velocidade média de $4 \mathrm{~km} \mathrm{~h}^{-1}$, como recomendado por Silveira (1989), para semeadoras-adubadoras com mecanismo dosador de semente tipo disco perfurado.

A primeira avaliação foi a contagem do número de paradas do conjunto trator-semeadora, em função do embuchamento, no percurso total de $1500 \mathrm{~m}$. Na seqüência, os dados foram coletados em esquema de grade com 75 pontos eqüidistantes $(10 \times 8,1 \mathrm{~m})$, distribuídos em 5 linhas e 15 colunas, para cada semeadora-adubadora. Em cada ponto da malha, sempre no sentido de ida da semeadora-adubadora, foram feitas três observações espaçadas $1 \mathrm{~m}$ em cada uma das nove linhas de semeadura, avaliando-se: sementes expostas (dentro do sulco, porém mal cobertas); sementes fora do sulco (na superfície); palha afundada; embuchamento (acúmulo de palha) e solo exposto (sem cobertura vegetal na linha de semeadura). Avaliou-se também, em cada linha de semeadura: a largura de revolvimento do sulco, medindo-se com trena a abertura feita pelos sulcadores; a profundidade de deposição da semente, através de 
abertura de trincheira na linha e auxílio de régua; a profundidade do sulco, com o auxílio de uma haste graduada e o número de plantas emergidas aos 21 dias após a semeadura, contando-se as plantas contidas em 2 m lineares. A massa seca de palha foi avaliada em $60 \%$ dos pontos, coletando-se três amostras de todo material contido em uma armação metálica quadrada de $0,16 \mathrm{~m}^{2}$.

Utilizou-se a análise de variância para comparar o desempenho de cada uma das linhas das semeadoras-adubadoras e se confrontaram as duas situações estudadas, através da análise conjunta de experimentos, com auxílio do programa estatístico SAS. Com ajuda da tecnologia SIG-IDRISI 32, obtiveram-se cartas espacializadas, cujo elemento temático foi o coeficiente de variação (CV\%) estratificado em classes.

\section{RESULTADOS E DISCUSSÃO}

\section{Número de paradas devido ao embuchamento}

Em um percurso de 1500 m (5 vezes ida e volta) o sistema com disco de corte da palha e haste sulcadora originais, determinou 23 paradas, confirmando o problema indicado no diagnóstico regional. A semeadora-adubadora com o sistema modificado exigiu apenas 3 paradas em virtude do embuchamento. Esta avaliação indica que, na prática, o sistema modificado apresenta vantagens em relação ao sistema original, pois com menor número de paradas há maior rendimento operacional. Segundo Klein et al. (2002), alta capacidade operacional é fundamental, de vez que condições ideais de semeadura, principalmente em relação à umidade do solo adequada, são temporárias.

\section{Freqüências de sementes expostas, sementes depositadas na superfície do solo, palha afundada, embuchamento e solo exposto}

A Tabela 1 apresenta os valores médios das freqüências de sementes expostas, sementes depositadas na superfície do solo, palha afundada, embuchamento e solo exposto. O va- lor de $100 \%$ de freqüência na linha significa a ocorrência da variável analisada nas três observações espaçadas, $1 \mathrm{~m}$. Quando nenhuma das três observações apresentou ocorrência, a freqüência anotada foi zero.

Apesar das freqüências de sementes expostas e sementes depositadas na superfície do solo não diferirem entre as linhas de semeadura da semeadora-adubadora original, apresentando médias de 7,5 e 11,9\%, respectivamente, em quase $20 \%$ dos pontos de avaliação havia pelo menos uma semente mal coberta por solo ou depositada sobre sua superfície, constituindo perda de sementes, prejudicando o estabelecimento da população desejada.

A semeadora-adubadora original apresentou afundamento de palha e embuchamento com freqüências estatisticamente semelhantes em todas as linhas de semeadura, com médias de 6,7 e 6,1\%, respectivamente. Quando o volume de palha na superfície é grande, ou seja, acima de $6 \mathrm{t} \mathrm{ha-1}$, e o espaçamento entre linhas da semeadora é reduzido (menor ou igual a $50 \mathrm{~cm}$ ), a possibilidade de ocorrer embuchamento é maior, em especial quando se utilizam sulcadores tipo haste (Araújo et al., 2001).

Apenas duas linhas de semeadura destacaram das demais na freqüência de solo exposto e esta diferença pode ser explicada pelo tipo de resíduo da cultura do milho que, por se constituir de partes vegetativas mais grossas, como pedaços de colmo e palha da espiga, dificulta sua distribuição, de maneira uniforme, na área. Segundo Casão Júnior et al. (2000), a ocorrência de solo exposto é reflexo da movimentação excessiva de solo provocada pelos sulcadores tipo haste, que o deixa sem a devida cobertura com palha. A cobertura do solo com palha, característica no sistema plantio direto, contribui para um ambiente apropriado à germinação e emergência das plantas, além de promover o controle da erosão.

Com relação à semeadora-adubadora modificada, as freqüências de sementes expostas e depositadas na superfície do solo não diferiram entre as linhas de semeadura e apresentaram médias de 6,7 e 12,2\%, respectivamente (Tabela 1).

Tabela 1. Freqüências de ocorrência de sementes expostas, sementes depositadas na superfície do solo, palha afundada, embuchamento e solo exposto, proporcionadas pelas semeadoras-adubadoras original e modificada ${ }^{1}$

\begin{tabular}{|c|c|c|c|c|c|c|c|c|c|c|}
\hline \multirow{4}{*}{ Linha } & \multicolumn{4}{|c|}{ Semente } & \multicolumn{4}{|c|}{ Palha } & \multirow{2}{*}{\multicolumn{2}{|c|}{ Solo exposto }} \\
\hline & \multicolumn{2}{|c|}{ exposta } & \multicolumn{2}{|c|}{ superfície } & \multicolumn{2}{|c|}{ afundada } & \multicolumn{2}{|c|}{ embuchada } & & \\
\hline & original & modificada & original & modificada & original & modificada & original & modificada & original & modificada \\
\hline & \multicolumn{10}{|c|}{$\%$} \\
\hline 1 & $11,5 \mathrm{a}$ & $9,3 \mathrm{a}^{2}$ & $12,4 \mathrm{a}$ & $14,6 \mathrm{a}$ & $8,5 \mathrm{a}$ & $16,8 \mathrm{a}$ & $6,2 \mathrm{a}$ & $0,9 a$ & $38,7 \mathrm{abc}$ & $33,3 \mathrm{c}$ \\
\hline 2 & $8,4 \mathrm{a}$ & $5,3 \mathrm{a}$ & $17,3 \mathrm{a}$ & $12,4 \mathrm{a}$ & $6,2 \mathrm{a}$ & $10,1 \mathrm{a}$ & $6,2 \mathrm{a}$ & $2,2 \mathrm{a}$ & 32,9 bc & $34,2 \mathrm{c}$ \\
\hline 3 & $5,3 \mathrm{a}$ & $5,7 \mathrm{a}$ & $8,4 \mathrm{a}$ & $14,2 \mathrm{a}$ & $4,9 \mathrm{a}$ & $12,8 \mathrm{a}$ & $5,8 \mathrm{a}$ & $0,9 \mathrm{a}$ & $43,1 \mathrm{abc}$ & $39,1 a b c$ \\
\hline 4 & $8,8 \mathrm{a}$ & $5,7 \mathrm{a}$ & $8,0 \mathrm{a}$ & $14,2 \mathrm{a}$ & $5,7 \mathrm{a}$ & $16,4 \mathrm{a}$ & $5,3 \mathrm{a}$ & $0,4 \mathrm{a}$ & $40,9 a b c$ & $24,9 \mathrm{c}$ \\
\hline 5 & $9,8 \mathrm{a}$ & $9,3 \mathrm{a}$ & $10,2 \mathrm{a}$ & $14,6 \mathrm{a}$ & $9,7 \mathrm{a}$ & $17,7 \mathrm{a}$ & $6,2 \mathrm{a}$ & $0,0 \mathrm{a}$ & 46,2 ab & $33,3 \mathrm{bc}$ \\
\hline 6 & $4,8 \mathrm{a}$ & $8,4 \mathrm{a}$ & $13,7 \mathrm{a}$ & $14,6 \mathrm{a}$ & $5,7 \mathrm{a}$ & $10,6 \mathrm{a}$ & $5,8 \mathrm{a}$ & $0,0 \mathrm{a}$ & $39,9 a b c$ & $35,5 \mathrm{bc}$ \\
\hline 7 & $7,9 \mathrm{a}$ & $9,3 \mathrm{a}$ & $9,3 \mathrm{a}$ & $7,9 \mathrm{a}$ & $5,7 \mathrm{a}$ & $12,4 \mathrm{a}$ & $7,1 \mathrm{a}$ & $0,0 \mathrm{a}$ & $49,8 \mathrm{a}$ & $51,6 a b$ \\
\hline 8 & $4,8 \mathrm{a}$ & $3,1 \mathrm{a}$ & $14,6 \mathrm{a}$ & $10,2 \mathrm{a}$ & $6,6 \mathrm{a}$ & $9,7 \mathrm{a}$ & $5,8 \mathrm{a}$ & $0,9 a$ & 33,3 bc & 54,6 a \\
\hline 9 & $5,7 \mathrm{a}$ & $4,4 \mathrm{a}$ & $13,3 \mathrm{a}$ & $7,1 \mathrm{a}$ & $7,5 \mathrm{a}$ & $17,3 \mathrm{a}$ & $6,2 \mathrm{a}$ & $2,7 \mathrm{a}$ & $27,9 \mathrm{c}$ & 34,2 bc \\
\hline Média & 7,5 & 6,7 & 11,9 & 12,2 & 6,7 & 13,7 & 6,1 & 0,9 & 39,2 & 37,9 \\
\hline Teste F & ns & ns & ns & ns & ns & ns & ns & ns & ** & $* *$ \\
\hline CV\% & 54,59 & 54,44 & 57,55 & 58,09 & 50,99 & 56,26 & 33,44 & 28,22 & 46,08 & 49,10 \\
\hline
\end{tabular}


A freqüência de solo exposto foi diferente entre algumas das linhas de semeadura, refletindo mais uma vez a excessiva movimentação de solo causada pela haste, que deixa o solo sem a cobertura de palha (Casão Júnior et al., 2000) e a dificuldade de cobertura uniforme da área, devido ao tipo de palha.

A freqüência de embuchamento acompanhou a contagem do número de paradas da máquina; apenas em 0,9\% dos pontos avaliados se observou a ocorrência de embuchamento.

Largura de revolvimento do solo, profundidade de deposição da semente e do sulco e número de plantas emergidas

A semeadora-adubadora original apresentou diferença nas profundidades de deposição da semente e de sulco, entre as linhas de semeadura (Tabela 2), porém os valores estão entre os previamente determinados pela regulagem. As diferenças na profundidade do sulco entre as linhas não influenciaram a largura de solo revolvido.

O coeficiente de variação para profundidade de deposição de semente foi $26,74 \%$, semelhante ao encontrado por Mantovani et al. (1992) em Latossolo Vermelho-Escuro com preparo convencional e maior que os obtidos por Oliveira et al. (2000), em Latossolo Vermelho-Amarelo e em Podzólico Vermelho-Amarelo em plantio direto, ambos na semeadura do milho. Casão Júnior \& Siqueira (2003) avaliando diversas semeadoras-adubadoras de plantio direto no oeste paranaense, encontraram valores de coeficiente de variação da profundidade da semente entre 20 e $43 \%$ na semeadura de soja e entre 17 e $32 \%$ na semeadura de feijão. O coeficiente de variação para a profundidade do sulco, de 21,15\%, foi acima dos valores encontrados por Casão Júnior \& Siqueira (2003).

O número de plantas emergidas foi semelhante em todas as linhas de semeadura e o valor médio encontrado foi superior ao almejado para deposição.

No sistema modificado, a largura de revolvimento do solo foi de 0,146 m, não apresentando diferença entre as linhas de semeadura. As profundidades de deposição da semente diferiram apenas entre as linhas 3 e 9 e a profundidade de sulco da linha de semeadura 3 diferiu das linhas 4, 5, 7 e 8 (Tabela 2); no entanto, as diferenças são mínimas e os valores estavam conforme prévia regulagem na semeadora-adubadora.

O coeficiente de variação da profundidade de semeadura, de $28,04 \%$, foi maior que os obtidos por Oliveira et al. (2000), semelhante ao encontrado por Mantovani, et al. (1992) e dentro da faixa encontrada por Casão Júnior \& Siqueira (2003). O coeficiente de variação da profundidade do sulco de 11,36\% está entre os valores adotados por Casão Júnior \& Siqueira (2003), que atribuem tal fato à ausência de um mecanismo controlador da profundidade das hastes sulcadoras, que permitiria manter a mesma angulação de ataque ao solo, nas diferentes condições do terreno.

As linhas de semeadura da semeadora-adubadora modificada apresentaram diferença quanto ao número de plantas emergidas (Tabela 2), porém os valores ficaram próximos ao almejado.

\section{Análise de variância conjunta dos ensaios}

A análise de variância conjunta é a comparação entre os resultados dos ensaios da semeadora-adubadora original e da semeadora-adubadora modificada, ilustrada na Tabela 3, e mostra que não houve diferença significativa entre as freqüências de sementes exposta e depositada na superfície e a freqüência de solo exposto entre as semeadoras-adubadoras. Nota-se que o sistema modificado não alterou, portanto, a cobertura do solo com palha, fator importante para garantir as vantagens do sistema plantio direto.

Na semeadora-adubadora com o sistema modificado, o desalinhamento dos conjuntos de disco e haste em relação ao carrinho da semente, visando à deposição do fertilizante abaixo e 0,03 m ao lado da semente, aliado à movimentação excessiva do solo, causou o maior enterrio da palha; esse desalinhamento não foi utilizado na semeadora-adubadora original. A palha enterrada pode formar espaços de

Tabela 2. Largura de revolvimento do solo, profundidades de deposição da semente e de sulco e número de plantas emergidas produzidas pelas semeadoras-adubadoras original e modificada ${ }^{1}$

\begin{tabular}{|c|c|c|c|c|c|c|c|c|}
\hline \multirow{4}{*}{ Linha } & \multirow{2}{*}{\multicolumn{2}{|c|}{$\begin{array}{c}\text { Largura } \\
\text { Revolvimento }\end{array}$}} & \multicolumn{4}{|c|}{ Profundidade } & \multirow{2}{*}{\multicolumn{2}{|c|}{$\begin{array}{c}\text { Plantas } \\
\text { emergidas }\end{array}$}} \\
\hline & & & \multicolumn{2}{|c|}{ Semente } & \multicolumn{2}{|c|}{ Sulco } & & \\
\hline & Original & Modificada & Original & Modificada & Original & Modificada & Original & Modificada \\
\hline & \multicolumn{6}{|c|}{$\mathrm{cm}$} & \multicolumn{2}{|c|}{ plantas ha-1 } \\
\hline 1 & $11,2 \mathrm{a}$ & $14,7 \mathrm{a}$ & $4,1 \mathrm{abc}$ & $4,6 a b$ & $9,1 \mathrm{~b}$ & $13,3 \mathrm{a}$ & 506.516 a & $402.366 \mathrm{~d}$ \\
\hline 2 & $11,3 \mathrm{a}$ & $14,6 \mathrm{a}$ & $4,2 \mathrm{abc}$ & $4,4 a b$ & $8,5 \mathrm{bc}$ & $12,8 a b$ & $502.365 \mathrm{a}$ & $440.440 \mathrm{c}$ \\
\hline 3 & $11,4 \mathrm{a}$ & 14,6 a & $4,1 \mathrm{abc}$ & $4,1 \mathrm{~b}$ & $8,5 \mathrm{bc}$ & $13,1 \mathrm{a}$ & 517.624 a & $452.440 \mathrm{c}$ \\
\hline 5 & $11,4 \mathrm{a}$ & $14,6 \mathrm{a}$ & $3,7 \mathrm{c}$ & $4,5 a b$ & $7,8 \mathrm{c}$ & 12,2 bc & $524.291 \mathrm{a}$ & $443.403 \mathrm{c}$ \\
\hline 6 & $11,4 \mathrm{a}$ & $14,5 \mathrm{a}$ & $4,0 \mathrm{bc}$ & $4,4 a b$ & $7,9 \mathrm{c}$ & $13,1 \mathrm{a}$ & $506.897 \mathrm{a}$ & $469.773 \mathrm{abc}$ \\
\hline 7 & $11,3 \mathrm{a}$ & $14,6 \mathrm{a}$ & $4,4 a b$ & $4,4 a b$ & $9,2 \mathrm{~b}$ & $11,2 \mathrm{~d}$ & 529.070 a & $489.032 \mathrm{a}$ \\
\hline 8 & $11,3 \mathrm{a}$ & $14,6 \mathrm{a}$ & $4,0 \mathrm{bc}$ & $4,3 a b$ & 8,6 bc & 12,2 bc & 530.580 a & $482.810 \mathrm{ab}$ \\
\hline 9 & $11,4 \mathrm{a}$ & $14,8 \mathrm{a}$ & $4,6 \mathrm{a}$ & $4,8 \mathrm{a}$ & 10,3 a & $12,8 \mathrm{ab}$ & $528.047 \mathrm{a}$ & $443.996 \mathrm{c}$ \\
\hline Média & 11,3 & 14,6 & 4,1 & 4,4 & 8,7 & 12,5 & 519.002 & 453.592 \\
\hline Teste F & ns & ns & $\star \star$ & * & ** & ** & ns & ** \\
\hline
\end{tabular}

${ }^{1}$ Médias seguidas por letras iguais nas colunas, não diferem entre si pelo teste Tukey a $5 \%$ de probabilidade; ${ }^{2}$ ns, Não significativo; *, Significativo a $5 \%$ de probabilidade; **, Significativo a $1 \%$ de probabilidade 
Tabela 3. Análise de variância conjunta entre os ensaios da semeadora-adubadora original e o da semeadora-adubadora modificada

\begin{tabular}{|c|c|c|c|c|c|c|c|c|c|}
\hline \multirow{3}{*}{ Semeadora-adubadora } & \multicolumn{2}{|c|}{ Semente } & \multicolumn{2}{|c|}{ Palha } & \multirow{2}{*}{$\begin{array}{l}\text { Solo } \\
\text { exposto }\end{array}$} & \multicolumn{2}{|c|}{ Profundidade } & \multirow{2}{*}{$\begin{array}{c}\text { Largura } \\
\text { revolvimento }\end{array}$} & \multirow{3}{*}{$\begin{array}{c}\text { Plantas } \\
\text { emergidas } \\
\text { pl. ha-1 }\end{array}$} \\
\hline & Exposta & Superfície & Afundada & Embuchada & & Semente & Sulco & & \\
\hline & & & $\%$ & & & & $\mathrm{~cm}$ & & \\
\hline Original & 7,5 & 11,9 & 6,7 & 6,1 & 39,2 & 4,1 & 8,7 & 11,3 & 519.002 \\
\hline Modificada & 6,7 & 12,2 & 13,7 & 0,9 & 37,9 & 4,4 & 12,5 & 14,6 & 453.592 \\
\hline Teste F1 & ns & ns & ** & $\star \star$ & ns & ** & $\star \star$ & ** & ** \\
\hline $\mathrm{CV} \%$ & 54,52 & 57,82 & 54,59 & 31,53 & 47,59 & 27,47 & 15,48 & 7,61 & 13,07 \\
\hline
\end{tabular}

${ }_{1}$ ns, Não significativo; **, Significativo a $1 \%$ de probabilidade

ar (bolsões) nos sulcos, que impedem um contato adequado solo-semente, prejudicando a germinação.

A freqüência de embuchamento acompanhou a contagem do número de paradas da máquina apresentando-se menor no sistema modificado confirmando, assim, que as modificações realizadas atingiram o objetivo proposto. O sistema modificado, apesar de minimizar a freqüência de embuchamento, prejudicou outras variáveis também importantes para a qualidade da operação de semeadura, como palha afundada e profundidade do sulco e da semente; entretanto, esses problemas podem ser sanados por meio de regulagens adequadas na semeadora-adubadora modificada.

A profundidade de trabalho da haste sulcadora foi maior na semeadora-adubadora modificada e influenciou a largura de revolvimento do solo, provavelmente por haver atingido regiões mais úmidas, aumentando a aderência de solo nos sulcadores. Segundo Araújo et al. (2001) a abertura de sulcos mais largos e o aumento da mobilização do solo é um dos efeitos mais evidentes da aderência de solo nos sulcadores que, por sua vez, é influenciada pelos teores de argila e de água no solo. Oliveira (2000) estudou a mobilização do solo realizada por dois tipos de hastes em semeadoras-adubadoras e concluiu que a correta regulagem e a escolha do teor de água adequado no solo podem induzir a menores mobilizações.

A maior freqüência de embuchamento no sistema original pode ter sido a causa do acréscimo do número de plantas emergidas em relação ao sistema modificado e ao almejado, pois os pontos de avaliação, que eram fixos, algumas vezes coincidiram com áreas próximas aos acúmulos de palha decorrentes do embuchamento, onde fôra depositado um número maior de sementes, evidenciando o problema enfrentado pelos agricultores, que reflete na qualidade da operação.

A distribuição espacial dos dados de coeficiente de variação entre os pontos da malha (Figura 1) possibilita melhor visualização da qualidade da semeadura; para a variável profundidade de deposição da semente, o resultado foi bastante semelhante, destacando-se apenas alguns pontos mais escuros (maior variação) no mapa da área de avaliação da semeadora-adubadora original; já para profundidade do sulco e largura de revolvimento do solo, a semeadora-adubadora original produziu, respectivamente, 5 e 53\% do total da área com a classe mais baixa de coeficiente de variação, ou seja, foi menos uniforme que a semeadoraadubadora com o sistema modificado que produziu o correspondente a 88 e 95\%. A porcentagem das áreas abrangidas com a menor classe de coeficiente de variação para o

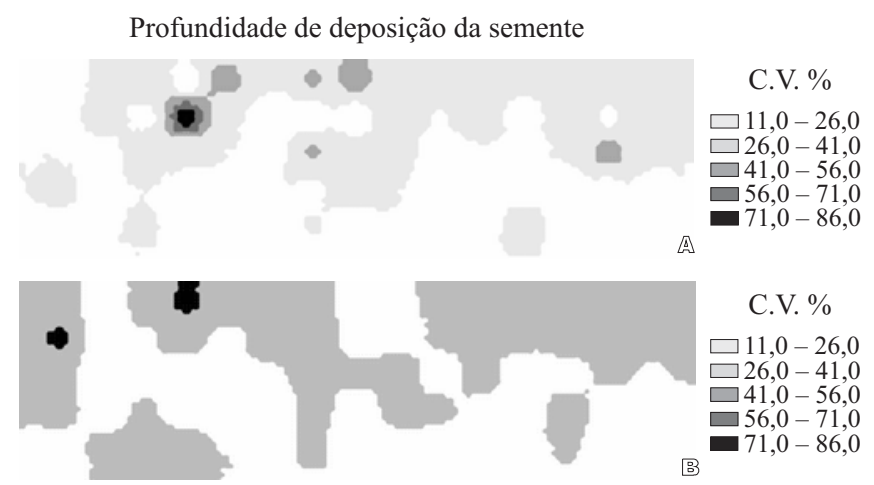

Profundidade do sulco
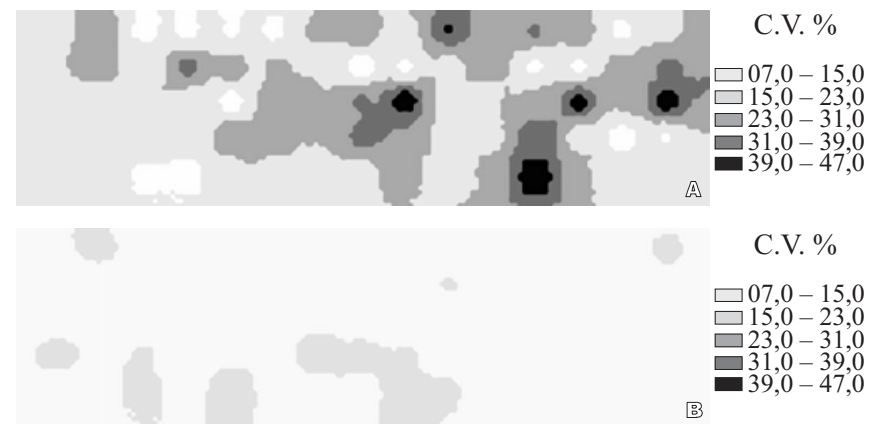

Revolvimento do solo

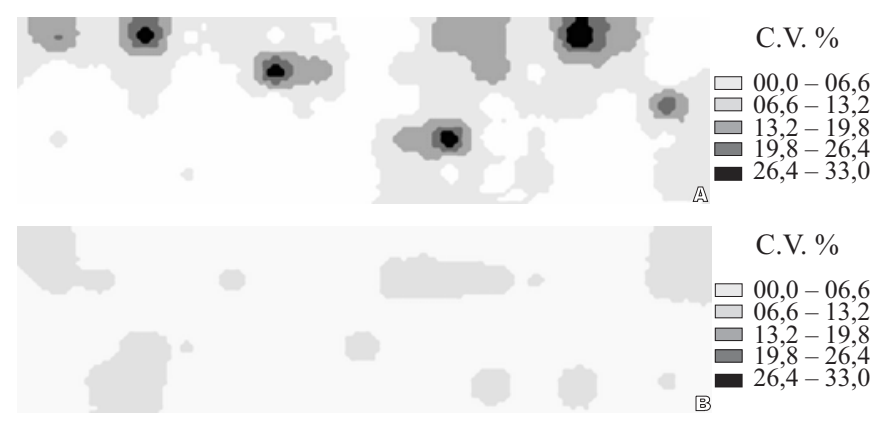

Plantas emergidas

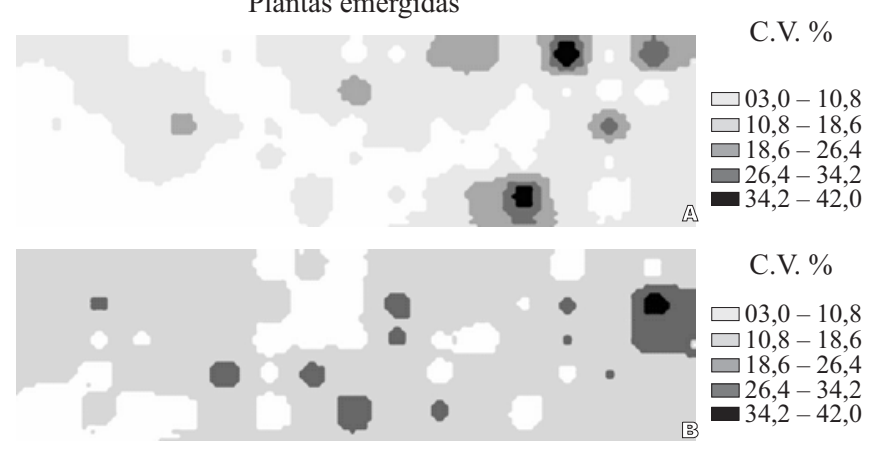

Figura 1. Espacialização dos dados de coeficiente de variação (\%) nas áreas de avaliação da semeadora-adubadora com os sistemas original (A) e modificado (B) 
número de plantas emergidas, foi maior na da semeadoraadubadora com o sistema original, mas na área de avaliação da semeadora-adubadora modificada ocorreu maior uniformidade. O restante das áreas enquadrou-se dentro das outras classes, com tonalidade mais escura no mapa, indicando maiores variações entre as linhas de semeadura; por outro lado e para a profundidade de semente, chama-se a atenção os altos valores de coeficiente de variação entre as linhas de cada semeadora, desde a classe mais baixa (11 a 26\%), levando-se em consideração que as mesmas apresentavam mecanismo especializado para tal função. Valores elevados de coeficiente de variação para a profundidade da semente, também foram constatados por Casão Júnior \& Siqueira (2003) em avaliações do desempenho de semeadoras-adubadoras diretas, no oeste paranaense. Silva et al. (2000) relatam que maior profundidade do sulco provoca também maior deslocamento de solo, em comparação com os sulcos mais rasos, dos sulcadores de disco; conseqüentemente, o solo é depositado nas laterais do sulco de plantio, por onde trafegam as rodas controladoras de profundidade, culminando na alteração da profundidade de semeadura.

\section{CONCLUSÕES}

1. O sistema modificado diminuiu o número de paradas, devido a pouco embuchamento.

2. As freqüências de solo exposto e profundidade da semente e do sulco em ambas as semeadoras-adubadoras, e o número de plantas emergidas para a semeadora-adubadora modificada, apresentaram diferença significativa entre as linhas de semeadura.

3. O sistema modificado desempenha operação mais uniforme.

4. O desempenho das duas semeadoras-adubadoras avaliadas não foi satisfatório quanto à largura de revolvimento do solo e ao coeficiente de variação da profundidade da semente.

\section{AgRADECIMENTOS}

Aos agricultores Giusepe e Salvatore de Angelis (Pedrinhas Paulista, SP), e Leonardo Coda (Florínea, SP), proprietários das áreas onde foram desenvolvidos os ensaios, e à Cooperativa dos Cafeicultores da Média Sorocabana - Coopermota (Cândido Mota, SP), à Associação de Plantio Direto do Vale do Paranapanema (Assis, SP) e a indústria Semeato (Passo Fundo, RS), pelo apoio financeiro ao projeto.

\section{LITERATURA CITADA}

Alves, A. G. C.; Cogo, N. P.; Levien, R. Relações da erosão do solo com a persistência da cobertura vegetal morta. Revista Brasileira de Ciência do Solo, Campinas, v.19, p.127-132, 1995.

Araújo, A. G.; Casão Júnior, R.; Siqueira, R. Mecanização do plantio direto: problemas e soluções. Londrina: Instituto Agronômico do Paraná. 2001, 18p. Informe da Pesquisa, n.137

Casão Júnior, R.; Araújo, A. G. de.; Ralisch, R. Desempenho da semeadora-adubadora Magnum 2850 em plantio direto no basalto paranaense. Pesquisa Agropecuária Brasileira, Brasília, v.35, n.3, p.523-532, 2000.

Casão Júnior, R.; Siqueira, R. Resultado das avaliações do desempenho de semeadoras adubadoras diretas na costa oeste paranaense. Londrina: IAPAR, 2003. 132p.

EMBRAPA - Empresa Brasileira de Pesquisa Agropecuária. Avaliação do desempenho de plantadoras diretas para culturas de verão. Centro Nacional de Pesquisa de Trigo. Passo Fundo: EMBRAPA, 1994. s.p.

Klein, V. A.; Siota, T. A.; Anesi, A. L.; Barbosa, R. Efeito da velocidade na semeadura direta de soja. Engenharia Agrícola, Jaboticabal, v.22, n.1, p.75-82, 2002.

Lombardi Neto, F.; Maria, I. C. de; Castro, O. M. de; Dechen, S. C. F.; Vieira, S. R. Efeito da quantidade de resíduos culturais de milho nas perdas de solo e água. Revista Brasileira de Ciência do Solo, Campinas, v.12, p.71-75, 1988.

Lopes, P. R. C.; Cogo, N. P.; Levien, R. Eficácia relativa de tipo e quantidade de resíduos culturais espalhados uniformemente sobre o solo na redução da erosão hídrica. Revista Brasileira de Ciência do Solo, Campinas, v.11, n.1, p.71-5, 1987.

Mantovani, E. C.; Bertaux, S.; Rocha, F. E. C. Avaliação da eficiência operacional de diferentes semeadoras-adubadoras de milho. Pesquisa Agropecuária Brasileira, Brasília, v.27, n.12, p.1579-1586, 1992.

Oliveira, M. F. B. Mobilização do solo por hastes sulcadoras de semeadoras-adubadoras de plantio direto. In: Congresso Brasileiro de Engenharia Agrícola, 29, 2000, Fortaleza. Anais... Fortaleza:SBEA, 2000. CD Rom

Oliveira, M. L. de.; Vieira, B. V.; Mantovani, E. C.; Souza, C. M. de.; Dias, G. P. Desempenho de uma semeadora-adubadora para plantio direto, em dois solos com diferentes tipos de cobertura vegetal. Pesquisa Agropecuária Brasileira, Brasília, v.35, n.7, p.1455-1463, 2000.

Silva, I. R. da; Lombardi Neto, F. Manejo dos restos culturais do milho e as perdas por erosão em Latossolo Roxo. In: Encontro Nacional de Pesquisa sobre Conservação do Solo, 3., 1980, Recife. Anais... Recife: SBCS, UFRPE, SUDENE, Empresa Pernambucana de Pesquisa Agropecuária, 1981. p.360-367.

Silva, J. G. S.; Kluthcouski, J.; Silveira, P. M. da. Desempenho de uma semeadora-adubadora no estabelecimento e na produtividade da cultura do milho sob plantio direto. Scientia Agrícola, Piracicaba, v.57, n.1, p.7-12, 2000.

Silveira, G. M. da. As máquinas para plantar. Rio de Janeiro: Globo, 1989. 257p. Coleção do Agricultor - Mecanização 